
RESEARCH AND DEVELOPMENT

\author{
http://journal.unnes.ac.id/sju/index.php/higeia
}

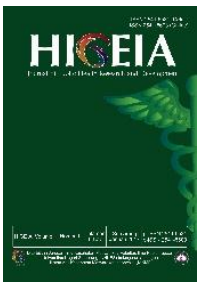

\title{
Faktor Lingkungan dan Perilaku terhadap Kejadian Demam Tifoid
}

\author{
Anggit Aprindrian Prehamukti ${ }^{\bowtie}$
}

Jurusan Ilmu Kesehatan Masyarakat, Fakultas Ilmu Keolahragaan, Universitas Negeri Semarang, Indonesia

\begin{tabular}{l}
\hline Info Artikel \\
\hline Sejarah Artikel: \\
Diterima 29 Juli 2018 \\
Disetujui 19 Oktober \\
2018 \\
Dipublikasikan 30 \\
Oktober 2018 \\
\hline Keywords: \\
Typhoid, Snacking \\
Behavior, Personal Hygiene \\
\hline DOI: \\
https://doi.org/10.15294 \\
/higeia.v2i4.24275
\end{tabular}

higeia.v2i4.24275

\begin{abstract}
Abstrak
Demam tifoid di Kota Semarang, khususnya wilayah kerja Puskesmas Ngaliyan tahun 2016 sebesar 423 kasus dan meningkat 57,5\% di tahun 2017 sebesar 736 kasus. Tujuan penelitian ini untuk mengetahui faktor yang paling berhubungan dengan kejadian demam tifoid di wilayah Kerja Puskesmas Ngaliyan. Penelitian ini dilaksanakan pada bulan Juli 2018. Jenis penelitian yang digunakan adalah analitik observasional dengan rancangan penelitian kasus kontrol. Sampel sebesar 34 kasus dan 34 kontrol dengan teknik purposive sampling. Instrumen menggunakan kuesioner dan lembar observasi. Data dianalisis menggunakan uji chi square dan regresi logistik dengan perangkat SPSS. Hasil penelitian menunjukkan ada hubungan antara perilaku jajan di rumah makan $(p=0,006)$, perilaku jajan di pedagang kaki lima $(p=0,001)$, dan kebiasaan cuci tangan dengan sabun sebelum makan $(p=0,029)$ dengan kejadian demam tifoid di Wilayah Kerja Puskesmas Ngaliyan. Variabel yang berkontribusi kuat untuk menduga kejadian demam tifoid adalah perilaku jajan di pedagang kaki lima $(p=0,008)$. Simpulan penelitian, terdapat hubungan antara perilaku jajan di rumah makan dan pedagang kaki lima, serta kebiasaan cuci tangan dengan sabun sebelum makan dengan kejadian demam tifoid.
\end{abstract}

\begin{abstract}
Typhoid fever in the city of Semarang, especially in the work area of Ngaliyan Health Center 2016 by 423 cases and increased 57.5\% in 2017 of 736 cases. The aim of this study is to determine factors were the most associated with the incidence of typhoid fever in Ngaliyan Health Center. This research was carried out in July 2018 and unmatched case control study. Samples were 34 cases and 34 controls using purposive sampling technique. The instrument used a questionnaire and observation sheet. Data were analyzed with chi square test and logistic regression with SPSS. Results showed there were relationship between snacking behavior in restaurant $(p=0,006)$, snacking behavior in street vendors $(p=0,001)$, and the habit of washing hands with soap before eating $(p=0,029)$ with the incidence of typhoid fever. Variable was the most contributed is snacking behavior in street vendors $(p=0,008)$. Conclusions of the study, there was a relationship between snack behavior in restaurants, street vendors, and washing hands with soap habits before eating with the incidence of typhoid fever.
\end{abstract}

(C) 2018 Universitas Negeri Semarang

$凶$ Alamat korespondensi:

Gedung F5 Lantai 2 FIK Unnes

p ISSN 1475-362846

Kampus Sekaran, Gunungpati, Semarang, 50229

e ISSN 1475-222656

E-mail: anggitaprin25@gmail.com 


\section{PENDAHULUAN}

Demam tifoid merupakan penyakit demam akut yang disebabkan bakteri Salmonella typhi (UI, 2010). Salmonella typhi disebarkan melalui rute fekal-oral yang memiliki potensi epidemi. WHO menyatakan penyakit demam tifoid di dunia mencapai 11-20 juta kasus per tahun yang mengakibatkan sekitar 128.000 . 161.000 kematian setiap tahunnya (WHO, 2018). Kasus demam tifoid di Indonesia dilaporkan dalam surveilans tifoid dan paratifoid Nasional. Demam tifoid masih umum terjadi di negara berkembang, hal ini mempengaruhi sekitar 21,5 juta orang setiap tahun. Wabah demam tifoid dilaporkan di Jepang pertama kali selama 16 tahun, 3/7 pasien adalah pengunjung restoran sedangkan 4/7 pasien merupakan pekerja restoran (Kobayashi, 2016). Penyakit ini mencapai tingkat prevalensi $358-810 / 100.000$ penduduk di Indonesia. Kasus demam tifoid ditemukan di Jakarta sekitar 182,5 kasus setiap hari. Diantaranya, sebanyak $64 \%$ infeksi demam tifoid terjadi pada penderita berusia 3 - 19 tahun. Namun, rawat inap lebih sering terjadi pada orang dewasa (32\% dibanding anak $10 \%$ ) dan lebih parah. Kematian akibat infeksi demam tifoid di antara pasien rawat inap bervariasi antara 3,1 - 10,4\% (sekitar 5 - 19 kematian sehari) (Typhoid Fever: Indonesia's Favorite Disease, 2016). Berdasarkan data Profil Kesehatan Indonesia tahun 2010, demam tifoid menduduki peringkat ke-3 dengan jumlah penderita sebanyak 41.081 orang yaitu 19.706 laki-laki dan 21.375 perempuan. Sebanyak 274 penderita meninggal dunia.

Berdasarkan data Sistem Kewaspadaan Dini dan Respon (SKDR) Kementerian Kesehatan tahun 2016, kasus demam tifoid di Jawa Tengah cenderung fluktuatif. Pada tahun 2014 terdapat 17.606 kasus, turun pada tahun 2015 terdapat 13.397 kasus, dan naik kembali pada tahun 2016 menjadi 244.071 kasus. Distribusi suspek demam tifoid menurut tempat, kota Semarang menempati sepuluh besar penyakit tertinggi selama 4 tahun terakhir. Pada tahun 2016, kota Semarang menempati urutan ke-9 dari 35 kabupaten/kota di Jawa Tengah sebagai penderita demam tifoid terbanyak. Menurut Profil Kesehatan Indonesia tahun 2016, persentase Tempat Pengelolaan Makanan (TPM) yang memenuhi syarat kesehatan secara Nasional pada tahun 2016 adalah 13,66\%. Sedangkan persentase TPM yang memenuhi syarat di Jawa Tengah tahun 2016 sebesar $8,27 \%$. Capaian ini belum memenuhi target Renstra Kementerian Kesehatan 2016 untuk TPM memenuhi syarat kesehatan yaitu sebesar 14\%. Berdasarkan penelitian Pramitasari (2013) mendapatkan hasil bahwa kebiasaan jajan diluar penyediaan rumah $(p=0,001)$ mempengaruhi kejadian demam tifoid pada penderita yang dirawat di RSUD Ungaran. Penelitian Siddiqui (2015) mendapatkan hasil sebanyak 220 penjamah makanan, 209 orang lainnya, 19 $(9,1 \%)$ terjangkit S.enterica. Sebanyak $9(4,3 \%)$ terjangkit S.typhi dan 10 (4,7\%) non-typhoid. Demam tifoid di Kota Semarang sebesar 9721 kasus (2014), naik 99,7\% (2015) menjadi sebesar 9748 kasus. Pada tahun 2016 ditemukan sebesar 9748 kasus. Kasus demam tifoid di wilayah kerja Puskesmas Ngaliyan tahun 2016 sebesar 423 kasus dan meningkat $57,5 \%$ di tahun 2017 sebesar 736 kasus. Berdasarkan laporan PHBS Puskesmas Ngaliyan (2017), jumlah Tempat Pengolahan Makanan di Wilayah Kerja Puskesmas Ngaliyan pada tahun 2015 sebanyak 163 jenis. Hanya sebanyak $23(14,1 \%)$ tempat yang dinyatakan laik higiene dan sanitasi. Sedangkan pada penelitian Alba (2016) menyatakan bahwa responden hanya sesekali menggunakan sabun untuk mencuci alat makan $(79,73 \%)$, selalu mencuci peralatan dengan sabun $(8,11 \%)$, dan tidak pernah menggunakan sabun $(12,16 \%)$.

Salmonella typhi disebarkan melalui rute fekal-oral yang memiliki potensi epidemik. Port d'entre Salmonella typhi adalah usus, apabila seseorang menelan organisme ini sebanyak 107 bakteri, dosis dibawah 105 tidak menimbulkan penyakit. Penularan demam tifoid dapat terjadi melalui berbagai cara yang dikenal degan $5 \mathrm{~F}$ yaitu Food (makanan), Fingers (jari tangan/kuku), Fomitus (muntah), Fly (lalat), dan Faeces (tinja). Feses dan muntah dari penderita 
demam tifoid dapat menularkan bakteri Salmonella typhi kepada orang lain. Bakteri tersebut dapat ditularkan melalui perantara lalat. Apabila orang tersebut kurang memperhatikan kebersihan dirinya, maka Salmonella typhi akan masuk ke tubuh orang yang sehat (Zulkoni, 2011). Salmonella dapat berkembang biak untuk mencapai kadar infektif dan bertahan lama dalam makanan. Makanan yang sudah dingin dan dibiarkan di tempat terbuka merupakan media mikroorganisme yang lebih disukai.

Selain penderita tifoid, sumber penularan utama berasal dari carrier. Jamban adalah suatu ruangan yang mempunyai fasilitas pembuangan kotoran manusia yang terdiri atas tempat jongkok atau tempat duduk dengan leher angsa atau tanpa leher angsa (cemplung) yang dilengkapi dengan unit penampungan kotoran dan air untuk membersihkannya. Menurut Mubarak (2009) pertimbangan pembuangan kotoran yaitu tidak menjadi sumber penularan penyakit, tidak menjadi makanan dan sarang vektor penyakit, tidak menimbulkan bau busuk, tidak merusak keindahan, dan tidak menimbulkan pencemaran kepada sumber air minum. Faktor yang dapat mengakibatkan kasus demam tifoid terjadi di tempat tinggal penderita demam tifoid sebelumnya yaitu letak jamban dan sumber persediaan air. Jarak minimal yang direkomendasikan untuk jarak septic tank dengan sumber air bersih adalah 10 m. Hal ini dilakukan untuk mencegah kontaminasi bakteriologis dari septic tank ke sumber air bersih responden. Kondisi rumah yang berhubungan dengan kualitas air bersih perlu diperhatikan agar air bersih tidak mengalami pencemaran (Yonathan, 2013).

Makanan merupakan sesuatu yang pokok dalam hidup. Agar makanan dapat berfungsi sebagaimana mestinya, kualitas makanan harus diperhatikan. Kualitas tersebut mencakup pencegahan terjadinya kontaminasi makanan dengan zat-zat yang dapat mengakibatkan gangguan kesehatan. Sanitasi makanan adalah usaha untuk mengamankan dan menyelamatkan makanan agar tetap bersih, sehat, dan aman. Terdapatnya kontaminan dalam makanan dapat berlangsung melalui dua cara, yaitu kontaminasi langsung dan kontaminasi silang. Kontaminasi langsung terjadi pada bahan makanan mentah, baik tanaman maupun hewan. kontaminasi silang dapat terjadi selama makanan ada dalam tahap persiapan, pengolahan, pemasakan, maupun penyajian (Alamsyah, 2013). TPM adalah usaha pengelolaan makanan yang meliputi jasaboga atau katering, rumah makan dan restoran, industri makanan, warung, depot air minum, kantin, dan makanan jajanan. Berdasarkan Kepmenkes No 1098/Menkes/SK/VII/2003 tentang Persyaratan Higiene Sanitasi Rumah Makan dan Restoran, persyaratan higiene sanitasi yang harus dipenuhi meliputi Persyaratan lokasi dan bangunan, Persyaratan fasilitas sanitasi, Persyaratan dapur, rumah makan, dan gudang makanan, Persyaratan bahan makanan dan makanan jadi, Persyaratan pengolahan makanan, Persyaratan penyimpanan bahan makanan dan makanan jadi, Persyaratan penyajian makanan jadi, dan Persyaratan peralatan yang digunakan.

Air yang tidak bersih banyak mengandung bakteri penyebab penyakit. Bila digunakan, kuman berpindah ke tangan. Pada saat makan, kuman dengan cepat masuk ke dalam tubuh, yang bisa menimbulkan penyakit. Sabun dapat membersihkan kotoran dan membunuh kuman, karena tanpa sabun kotoran dan kuman masih tertinggal di tangan. Waktu yang tepat untuk cuci tangan adalah setiap kali tangan kita kotor (setelah; memegang uang, memegang binatang, berkebun, d1l), setelah buang air besar, setelah menceboki bayi atau anak, sebelum makan dan menyuapi anak, sebelum memegang makanan, dan sebelum menyusui bayi (RI, n.d.). Perbedaan penelitian ini dan penelitian sebelumnya adalah adanya perilaku jajan di TPM dan kondisi kuku jari tangan yang belum diteliti pada penelitian sebelumnya, serta dilengkapi dengan analisis multivariat. Sehingga penelitian ini bertujuan untuk mengetahui hubungan antara kondisi jamban, perilaku jajan di TPM, dan personal hygiene dengan kejadian demam tifoid di wilayah Kerja Puskesmas Ngaliyan serta faktor 
yang paling berkontribusi kuat terhadap kejadian demam tifoid.

\section{METODE}

Variabel penelitian yaitu terdiri dari variabel bebas, variabel terikat, dan variabel perancu. Variabel bebas pada penelitian ini yaitu kondisi jamban keluarga, perilaku jajan di rumah makan, perilaku jajan di pedagang kaki lima, perilaku jajan di pedagang keliling, kebiasaan mencuci tangan dengan sabun sebelum makan, kebiasaan mencuci tangan dengan sabun setelah $\mathrm{BAB}$, dan kondisi kuku jari tangan. Variabel terikat pada penelitian ini adalah kejadian demam tifoid pada penderita di wilayah kerja Puskesmas Ngaliyan kota Semarang. Variabel perancu yang ditemukan dalam penelitian ini adalah jenis kelamin, umur, dan pengetahuan.

Jenis penelitian yang digunakan dalam penelitian ini adalah analitik dengan studi observasional. Rancangan penelitian yang digunakan adalah studi kasus kontrol, yang menelaah hubungan antara efek kejadian demam tifoid dengan faktor risiko tertentu. Variabel kejadian demam tifoid dengan kategori penderita demam tifoid, dibuktikan dengan catatan medik yang ada di Puskesmas Ngaliyan dan bukan penderita demam tifoid, tidak menunjukkan gejala serupa dengan penderita demam tifoid. Kondisi jamban keluarga dengan kategori jamban sehat (memenuhi kriteria jamban sehat, dilihat dari bangunan atas, tengah, dan bawah jamban), bukan jamban sehat (tidak memenuhi kriteria jamban sehat), perilaku jajan di rumah makan, perilaku jajan di pedagang kaki lima, dan perilaku jajan di pedagang keliling dengan kategori berisiko $(\geq 3$ kali seminggu), tidak berisiko $(<3$ kali seminggu). Kebiasaan mencuci tangan dengan sabun sebelum makan dan kebiasaan mencuci tangan dengan sabun setelah $\mathrm{BAB}$ dengan kategori berisiko (tidak mencuci tangan dengan sabun), tidak berisiko (mencuci tangan dengan sabun). Kondisi kuku jari tangan dengan kategori berisiko (panjang kotor, pendek kotor), tidak berisiko (panjang bersih, pendek bersih).
Variabel perancu yaitu jenis kelamin dengan kategori berisiko (laki-laki), tidak berisiko (perempuan). Umur dengan kategori berisiko (anak-anak dan remaja usia < 19 tahun), tidak berisiko (dewasa usia $\geq 25$ tahun). Pengetahuan dengan kategori rendah (tidak sekolah, SD, SMP), tinggi (SMA, Perguruan tinggi/ akademi).

Populasi target dalam penelitian ini yaitu penderita dan bukan penderita demam tifoid. Populasi terjangkau yaitu penderita demam tifoid yang pernah dirawat di Puskesmas Ngaliyan dan bukan penderita yang bertempat tinggal di wilayah kerja Puskesmas Ngaliyan. Populasi kasus dalam penelitian ini adalah seluruh penderita Demam Tifoid pada bulan Januari 2016 - Januari 2018 sebanyak 128 kasus. Sementara populasi kontrol dalam penelitian ini adalah seluruh warga yang bukan penderita demam tifoid dan bertempat tinggal di wilayah kerja Puskesmas Ngaliyan. Sampel kasus dalam penelitian ini adalah pasien penderita demam tifoid, kriteria inklusi yaitu penderita demam tifoid usia $\geq 25$ tahun yang ditunjang dengan hasil uji widal positif dan tercatat dalam rekam medis Puskesmas Ngaliyan Januari 2016Januari 2018 dan bertempat tinggal tetap di Kecamatan Ngaliyan. Serta kriteria eksklusi yaitu tidak bersedia menjadi responden, jamban responden pernah direnovasi selama 1 tahun terakhir, serta alamat tidak jelas atau tidak dapat ditemui saat pelaksanaan penelitian selama 3 kali.

Sampel kontrol dalam penelitian ini adalah bukan penderita demam tifoid usia $\geq 25$ tahun dan tidak memiliki gejala serupa yang bertempat tinggal di wilayah kerja Puskesmas Ngaliyan. Serta kriteria eksklusi yaitu tidak bersedia menjadi responden, jamban responden pernah direnovasi selama 1 tahun terakhir, dan alamat tidak jelas atau tidak dapat ditemui saat pelaksanaan penelitian selama 3 kali. Besar sampel minimal yang didapat berdasarkan rumus perhitugan sampel minimal adalah sebesar 31 orang, kemudian ditambahkan spare $10 \%$ untuk menghindari drop out. Maka besar sampel penelitian ini adalah 34 orang. Pengambilan sampel untuk kasus dan kontrol 
menggunakan perbandingan 1:1, sehingga besar sampel penelitian ini adalah 34 sampel kasus dan 34 sampel kontrol. Jadi, jumlah sampel secara keseluruhan sebesar 68 sampel. Pengambilan sampel dilakukan dengan teknik purposive sampling.

Sumber data primer dalam penelitian ini adalah dengan menggunakan kuesioner dan lembar observasi mengenai jenis jamban keluarga, perilaku jajan di rumah makan, perilaku jajan di warung makan, perilaku jajan di pedagang kaki lima, kebiasaan mencuci tangan dengan sabun sebelum makan, kebiasaan mencuci tangan dengan sabun setelah $\mathrm{BAB}$, dan kondisi kuku jari tangan. Sedangkan sumber data sekunder dalam penelitian ini diperoleh dari rekam medis pasien demam tifoid di Puskesmas Ngaliyan. Instrumen yang digunakan dalam penelitian adalah rekam medis dari Puskesmas, kuesioner, dan lembar observasi. Teknik pengambilan data yaitu wawancara dan observasi. Analisis data menggunakan analisis univariat, bivariat, multivariat. Analisis bivariat dengan menggunakan uji chi-square, adapun untuk uji alternatifnya menggunakan Uji Fisher. Sedangkan analisis multivariat menggunakan logistic regression, dilakukan sebagai tindak lanjut dari uji bivariat dengan mengikutsertakan variabel yang bermakna secara statistik ( $p<$ $0,05)$ dan variabel yang mempunyai nilai $(p<$ 0,25 ) sebagai batas seleksi untuk menghindari kegagalan mengikutsertakan variabel yang diketahui penting.

\section{HASIL DAN PEMBAHASAN}

Lokasi yang menjadi sasaran penelitian ini yaitu wilayah kerja Puskesmas Ngaliyan yang mempunyai luas wilayah $28,33 \mathrm{~km}^{2}$ dengan jumlah penduduk 52.208 jiwa. Wilayah kerja Puskesmas Ngaliyan meliputi 6 kelurahan, yaitu Kelurahan Ngaliyan, Kelurahan Bambankerep, Kelurahan Gondoriyo, Kelurahan Beringin, Kelurahan Podorejo, dan Kelurahan Wates. Jumlah responden sebanyak 34 subjek kasus dan 34 subjek kontrol. Subjek kasus yaitu penderita demam tifoid usia $\geq 25$ tahun yang tercatat dalam rekam medis dan bertempat tinggal di Wilayah Kerja Puskesmas Ngaliyan. Subjek kontrol yaitu bukan penderita demam tifoid usia $\geq 25$ tahun dan tidak memiliki gejala serupa.

Karakteristik responden dalam penelitian ini dapat dilihat dari tempat tinggal dan pekerjaan responden pada gambar 1 .

Tabel 1. Tempat tinggal dan pekerjaan responden di wilayah kerja Puskesmas Ngaliyan Kota Semarang

\begin{tabular}{|c|c|c|c|c|c|}
\hline & Karakteristik & Kasus & Kontrol & Jumlah & $\%$ \\
\hline \multicolumn{6}{|c|}{$\begin{array}{l}\text { Wilayah Tempat Tinggal } \\
\text { (Kelurahan) }\end{array}$} \\
\hline & Kelurahan Bambankerep & 4 & 3 & 7 & 10,3 \\
\hline & Kelurahan Wates & 8 & 7 & 15 & 22,1 \\
\hline & Kelurahan Podorejo & 6 & 7 & 13 & 19,1 \\
\hline & Kelurahan Gondoriyo & 5 & 4 & 9 & 13,2 \\
\hline & Kelurahan Bringin & 7 & 8 & 15 & 22,1 \\
\hline & Kelurahan Ngaliyan & 4 & 5 & 9 & 13,2 \\
\hline \multicolumn{6}{|l|}{ Pekerjaan } \\
\hline & IRT & 10 & 12 & 22 & 32,4 \\
\hline & Dokter & 0 & 1 & 1 & 1,5 \\
\hline & Pedagang & 1 & 4 & 5 & 7,4 \\
\hline & Buruh & 9 & 3 & 12 & 17,6 \\
\hline & Guru & 2 & 1 & 3 & 4,4 \\
\hline & Petani & 2 & 4 & 6 & 8,8 \\
\hline & Wiraswasta & 2 & 3 & 5 & 7,4 \\
\hline & Swasta & 6 & 5 & 11 & 16,2 \\
\hline & PNS & 1 & 1 & 2 & 2,9 \\
\hline & Tidak bekerja & 1 & 0 & 1 & 1,5 \\
\hline
\end{tabular}


Karakteristik responden berdasarkan tempat tinggal pada penderita demam tifoid di wilayah kerja Puskesmas Ngaliyan menunjukkan bahwa jumlah responden yang paling banyak menderita demam tifoid terdapat di Kelurahan Wates dan Bringin yaitu sebanyak 15 orang $(22,1 \%)$ dan paling sedikit di Kelurahan Bambankerep sebanyak 7 orang $(10,3 \%)$. Sedangkan pada status pekerjaan memperlihatkan bahwa responden dengan jumlah terbanyak adalah ibu rumah tangga sebanyak 22 orang $(32,4 \%)$. Sedangkan status pekerjaan paling sedikit adalah dokter dan responden yang tidak bekerja dengan jumlah masing-masing 1 orang $(1,5 \%)$.

Hasil pengolahan data dapat dilihat pada tabel 2. Hasil analisis bivariat yang dilakukan pada variabel kondisi jamban diperoleh $p$-value $=$

Tabel 2. Hasil Analisis Bivariat dengan Menggunakan Uji Chi Square

\begin{tabular}{|c|c|c|c|c|c|c|c|c|c|}
\hline \multirow{3}{*}{ Variabel } & \multirow{3}{*}{ Kategori } & \multicolumn{4}{|c|}{ Frekuensi (n) } & \multirow{2}{*}{\multicolumn{2}{|c|}{ Jumlah }} & \multirow{3}{*}{$p$ value } & \multirow{3}{*}{$\begin{array}{l}\text { OR } \\
(95 \% \\
\text { CI })\end{array}$} \\
\hline & & \multicolumn{2}{|c|}{ Kasus } & \multicolumn{2}{|c|}{ Kontrol } & & & & \\
\hline & & $\mathrm{N}$ & $\%$ & $\mathrm{n}$ & $\%$ & $\mathrm{~N}$ & $\%$ & & \\
\hline \multirow[t]{2}{*}{ Kondisi Jamban } & \multirow{2}{*}{$\begin{array}{l}\text { Jamban sehat } \\
\text { Jamban tidak } \\
\text { sehat }\end{array}$} & 9 & 26,5 & 3 & 8,8 & 12 & 17,6 & & 3,7 \\
\hline & & 25 & 73,5 & 31 & 91,2 & 56 & 82,4 & 0,11 & $\begin{array}{c}(0,91- \\
15,2)\end{array}$ \\
\hline \multirow[t]{2}{*}{$\begin{array}{l}\text { Perilaku jajan di } \\
\text { rumah makan }\end{array}$} & $\begin{array}{l}\text { Berisiko }(\geq 3 \\
\text { kali dalam }\end{array}$ & 19 & 55,9 & 7 & 20,6 & 26 & 38,2 & & \\
\hline & $\begin{array}{l}\text { seminggu) } \\
\text { Tidak berisiko } \\
\text { (<3 kali dalam } \\
\text { seminggu) }\end{array}$ & 15 & 44,1 & 27 & 79,4 & 42 & 61,8 & 0,01 & $\begin{array}{l}(1,67- \\
14,27)\end{array}$ \\
\hline \multirow[t]{2}{*}{$\begin{array}{l}\text { Perilaku jajan di } \\
\text { pedagang kaki } \\
\text { lima }\end{array}$} & $\begin{array}{l}\text { Berisiko }(\geq 3 \\
\text { kali dalam } \\
\text { seminggu) }\end{array}$ & 26 & 76,5 & 12 & 35,3 & 38 & 55,9 & & 5,96 \\
\hline & $\begin{array}{l}\text { Tidak berisiko } \\
\text { (<3 kali dalam } \\
\text { seminggu) }\end{array}$ & 8 & 23,5 & 22 & 64,7 & 30 & 44,1 & 0,00 & $\begin{array}{c}(2,07- \\
17,19)\end{array}$ \\
\hline \multirow[t]{2}{*}{$\begin{array}{l}\text { Perilaku jajan di } \\
\text { pedagang } \\
\text { keliling }\end{array}$} & $\begin{array}{l}\text { Berisiko ( } \geq 3 \\
\text { kali dalam } \\
\text { seminggu) }\end{array}$ & 3 & 8,8 & 7 & 20,6 & 10 & 14,7 & & $\begin{array}{r}0,37 \\
0,09\end{array}$ \\
\hline & $\begin{array}{l}\text { Tidak berisiko } \\
(<3 \text { kali dalam } \\
\text { seminggu })\end{array}$ & 31 & 91,2 & 27 & 79,4 & 58 & 85,3 & 0,30 & $\begin{array}{c}(0,09- \\
1,59)\end{array}$ \\
\hline \multirow{2}{*}{$\begin{array}{l}\text { Kebiasaan } \\
\text { Mencuci } \\
\text { Tangan Sebelum } \\
\text { Makan }\end{array}$} & $\begin{array}{l}\text { Berisiko (cuci } \\
\text { tangan pakai } \\
\text { sabun) }\end{array}$ & 22 & 64,7 & 12 & 35,3 & 34 & 50 & & \\
\hline & $\begin{array}{l}\text { Tidak berisiko } \\
\text { (tidak cuci } \\
\text { tangan pakai } \\
\text { sabun) }\end{array}$ & 12 & 35,3 & 22 & 64,7 & 34 & 50 & 0,03 & $\begin{array}{l}(1,24- \\
9,09)\end{array}$ \\
\hline \multirow{2}{*}{$\begin{array}{l}\text { Kebiasaan } \\
\text { Mencuci } \\
\text { Tangan dengan } \\
\text { sabun Setelah } \\
\text { BAB }\end{array}$} & $\begin{array}{l}\text { Berisiko (cuci } \\
\text { tangan pakai } \\
\text { sabun) }\end{array}$ & 3 & 8,8 & 6 & 17,6 & 9 & 13,2 & & \\
\hline & $\begin{array}{l}\text { Tidak berisiko } \\
\text { (tidak cuci } \\
\text { tangan pakai } \\
\text { sabun) }\end{array}$ & 31 & 91,2 & 28 & 82,4 & 59 & 86,8 & 0,48 & $\begin{array}{c}(0,10- \\
1,98)\end{array}$ \\
\hline \multirow[t]{2}{*}{$\begin{array}{l}\text { Kondisi kuku } \\
\text { jari tangan }\end{array}$} & $\begin{array}{l}\text { Berisiko } \\
\text { (panjang kotor, } \\
\text { pendek kotor) }\end{array}$ & 22 & 64,7 & 16 & 47,1 & 38 & 55,9 & 0,22 & \multirow{2}{*}{$\begin{array}{c}2,1 \\
(0,78- \\
5,46)\end{array}$} \\
\hline & $\begin{array}{l}\text { Tidak berisiko } \\
\text { (panjang bersih, } \\
\text { pendek bersih) }\end{array}$ & 12 & 35,3 & 18 & 52,9 & 30 & 44,1 & & \\
\hline
\end{tabular}


$0,11(p>0,05)$ sehingga Ho diterima yang berarti tidak terdapat hubungan antara kondisi jamban dengan kejadian demam tifoid di Wilayah Kerja Puskesmas Ngaliyan. Menurut Febriana (2015) bakteri Salmonella typhi sering ditemukan di sumur-sumur yang telah terkontaminasi oleh feses manusia yang terinfeksi oleh Salmonella typhi. Hal ini dapat terjadi karena jarak lubang septik tank kurang dari $10 \mathrm{~m}$ dengan sumur gali. Sehingga bakteri Salmonella typhi yang berada dalam septik tank akan mengontaminasi air sumur yang digunakan untuk konsumsi keluarga.

Alasan mengapa tidak adanya hubungan antara kondisi jamban dengan kejadian demam tifoid karena diduga sumber air minum yang digunakan warga adalah air artetis dengan jarak $>10 \mathrm{~m}$ dari jamban. Sehingga kontaminasi bakteri Salmonella typhi dari septic tank warga tidak mengalami pencemaran. Menurut Peraturan Menteri Kesehatan Republik Indonesia Nomor 3 Tahun 2014 Tentang Sanitasi Total Berbasis Masyarakat jamban sehat efektif untuk memutus mata rantai penularan penyakit. Jamban sehat harus dibangun, dimiliki, dan digunakan oleh keluarga dengan penempatan (di dalam rumah atau di luar rumah) yang mudah dijangkau oleh penghuni rumah.

Pada variabel perilaku jajan di rumah makan, diperoleh $p$-value $=0,01 \quad(p<0,05)$ sehingga Ho ditolak Ha diterima yang berarti terdapat hubungan antara perilaku jajan di rumah makan dengan kejadian demam tifoid di Wilayah Kerja Puskesmas Ngaliyan. Pada perhitungan risk estimate didapatkan OR sebesar 4,9. Hal ini menunjukkan bahwa orang dewasa yang jajan di rumah makan $\geq 3$ kali seminggu berisiko 4,9 kali lebih besar terkena demam tifoid dibandingkan dengan orang dewasa yang jajan di rumah makan $<3$ kali seminggu. Hal ini sejalan dengan penelitian Syafdalni (2014) yang menyatakan bahwa rumah makan dan restoran tanpa grade tidak memenuhi 6 prinsip sanitasi pengelolaan makanan dan tidak memenuhi syarat dalam fasilitas sanitasinya. Seseorang yang mempunyai kebiasaan makan di luar rumah $\geq 3$ kali dalam seminggu mempunyai resiko 5,0 kali lebih besar terkena demam tifoid dari responden yang tidak memiliki kebiasaan makan di luar rumah $\geq 3$ kali dalam seminggu (Seran, 2015). Hal ini sejalan dengan penelitian Andayani (2017) yang menyatakan bahwa kebiasaan jajan makanan di luar rumah menjadi salah satu faktor risiko kejadian demam tifoid.

Alasan yang menduga perilaku jajan di rumah makan berhubungan dengan kejadian demam tifoid karena kebiasaan jajan responden kasus di rumah makan lebih sering dilakukan pada jam makan siang. Hal ini dikarenakan responden tidak berada dirumah pada jam tersebut. Rumah makan yang sering didatangi responden adalah tempat makan yang berbentuk rumah, bukan tenda. Sebagian responden yang sering jajan di rumah makan sering mendapati lalat yang berkeliaran dan hinggap di makanan yang terbuka. Hal ini dapat menjadi media transmisi penyakit yang disebabkan oleh vektor (lalat). Sanitasi makanan yang buruk dapat menimbulkan gangguan kesehatan pada orang yang mengonsumsinya. Gangguan kesehatan yang dapat terjadi akibat makanan dapat dikelompokkan menjadi keracunan makanan dan penyakit bawaan makanan (foodborne disease) (Alamsyah, 2013). Penelitian Onyeneho (2013) menunjukkan bahwa sebanyak 76 dari 155 (49\%) kepala koki restoran di Nigeria melaporkan bahwa mereka akan mengizinkan orang yang sakit untuk menangani makanan. Hanya 62 orang dari 155 (40\%) kepala koki yang memiliki pengetahuan tentang Salmonella. Hasil penelitian ini diperkuat pada penelitian Lee (2017) yang mendapatkan hasil bahwa dari penilaian kebersihan tangan pada 85 penjamah makanan yang berpartisipasi dalam penelitian ini mengungkapkan bahwa $65 \%(\mathrm{n}=55)$ dari mereka memiliki jumlah bakteri aerobik melebihi ambang diantaranya terdeteksi Salmonella pada 41 (48\%) penjamah makanan. Untuk meminimalisir faktor risiko terkena penyakit demam tifoid yang dapat ditularkan melalui jajan di rumah makan, perlu diperhatikan dalam intensitas jajan diluar rumah dengan membawa bekal ketika bekerja. 
Hasil analisis bivariat dengan uji chi-square diperoleh $p$-value $=0,00(p<0,05)$ sehingga $\mathrm{Ho}$ ditolak $\mathrm{Ha}$ diterima yang berarti terdapat hubungan antara perilaku jajan di pedagang kaki lima dengan kejadian demam tifoid di Wilayah Kerja Puskesmas Ngaliyan. Pada perhitungan risk estimate didapatkan OR sebesar 5,96. Hal ini menunjukkan bahwa orang dewasa yang jajan di pedagang kaki lima $\geq 3$ kali seminggu berisiko 5,96 kali lebih besar terkena demam tifoid dibandingkan dengan orang dewasa yang jajan di pedagang kaki lima $<3$ kali seminggu. Makanan dan minuman yang terkontaminasi merupakan mekanisme transmisi kuman Salmonella, termasuk S.typhi yang berada dalam air, es, debu, sampah kering, yang bila organisme ini masuk ke dalam vehicle yang cocok (daging, kerang) akan berkembang biak mencapai dosis infektif (UI, 2010), 2010). Hal ini sesuai dengan penelitian yang dilakukan oleh Susanna (2010) yang menyatakan bahwa faktor dominan yang mengontaminasi makanan yang dijajakan pedagang kaki lima adalah tempat sampah di tempat penjualan $(p=0,008$, $\mathrm{OR}=0,147)$, peralatan makanan dicuci dengan air tidak mengalir ( $p=0,411, \mathrm{OR}=0,363)$, alat makan dicuci dengan sabun $(p=0,547$, $\mathrm{OR}=0,517)$, dan kondisi penyajian makanan $(p=0,002 \mathrm{OR}=0,214)$. Penelitian yang dilakukan Monney (2013) menunjukkan bahwa sekitar $55,0 \%$ dari pedagang kaki lima diamati untuk melindungi makanan mereka dari lalat dan debu sementara $45,0 \%$ tidak memiliki perlindungan, sehingga tidak melindungi makanan mereka dari lalat dan debu.

Pedagang kaki lima beroperasi dari berbagai macam struktur tempat berjualan mulai dari membangun empat stan bertembok, membangun setengah empat warung bertiang, dan warung yang dikelilingi bahan plastik atau bahan tanaman (papyrus) dan udara terbuka. Bahan atap yang digunakan untuk tempat berjualan terutama lembaran besi atau lembaran plastik (Muyanja, 2011). Hal yang diduga perilaku jajan di pedagang kaki lima karena makanan yang dijual pada pedagang kaki lima adalah makanan yang belum diproses. Sehingga makanan tersebut diolah langsung saat proses pemesanan makanan. Infeksi Salmonella typhi pada umumnya terjadi karena mengkonsumsi makanan atau minuman yang tercemar akibat penanganan yang tidak higienis. Bakteri Salmonella typhii dapat ditularkan melalui makanan yang diolah oleh penjamah makanan jika tidak memperhatikan kebersihan diri dan kebersihan alat memasak. Hal ini diperkuat oleh penelitian yang dilakukan Omemu (2008) yaitu lebih banyak penjual makanan yang lebih mempertimbangkan volume (94\%) dan harganya (93\%) daripada kesegaran dan kebersihan saat membeli makanan bahan makanan untuk dimasak.

Hasil analisis bivariat dengan uji chi-square diperoleh $p$-value $=0,30(p>0,05)$ sehingga $\mathrm{Ho}$ diterima yang berarti tidak terdapat hubungan antara perilaku jajan di pedagang keliling dengan kejadian demam tifoid di Wilayah Kerja Puskesmas Ngaliyan. Hal yang diduga menyebabkan tidak adanya hubungan antara perilaku jajan di pedagang keliling dengan kejadian demam tifoid adalah responden kasus maupun kontrol jarang membeli makan di pedagang keliling karena akses pedagang keliling terkadang sulit masuk wilayah responden. Alasan lain yang diduga tidak adanya hubungan antara perilaku jajan di pedagang keliling dengan kejadian demam tifoid adalah berkurangnya minat responden dalam membeli makanan jajanan di pedagang keliling. Responden lebih memilih membuat makanan sendiri dirumah, seperti makanan pokok dan sayur dibandingkan membeli langsung jadi di pedagang keliling.

Pedagang keliling hanya menjual makanan jajanan anak. Perlu diperhatikan dalam membeli jajan di pedagang keliling dengan melihat sanitasi peralatan dan tempat yang digunakan untuk menjajakan dagangannya. Makanan jajanan yang dijajakan dengan sarana penjaja peralatan pengolahan harus dibersihkan sehingga dapat melindungi makanan dari bakteri Salmonella typhii.

Hasil analisis bivariat dengan uji chi-square diperoleh $p$-value $=0,03(p<0,05)$ sehingga $\mathrm{Ho}$ ditolak $\mathrm{Ha}$ diterima yang berarti terdapat hubungan antara kebiasaan CTPS sebelum 
makan dengan kejadian demam tifoid di Wilayah Kerja Puskesmas Ngaliyan. Pada perhitungan risk estimate didapatkan OR sebesar 3,4. Hal ini menunjukkan bahwa kebiasaan CTPS sebelum makan memiliki risiko terhadap kejadian demam tifoid sebesar 3,4 kali dibandingkan dengan responden yang memiliki kebiasaan CTPS sebelum makan. Pada penelitian Nuruzzaman (2016) yang meneliti pada anak usia $<17$ tahun menyatakan bahwa anak yang memiliki kebiasaan mencuci tangan sebelum makan yang kurang baik saat berada di rumah mempunyai risiko 4,33 kali mengalami demam tifoid dibandingkan anak dengan kebiasaan mencuci tangan sebelum makan yang baik saat berada di rumah. Menurut penelitian Pramitasari (2013) 61,9\% penderita demam tifoid memiliki kebiasaan yang kurang baik ketika mencuci tangan sebelum makan di mana mereka tidak mencuci tangan dengan air mengalir dan sabun serta menggosok sela-sela jari dan kuku sehingga bakteri Salmonella typhi bisa saja masih ada dibagian tersebut. Mencuci tangan dengan tidak menggunakan sabun dan tidak menggosok sela-sela jari tangan dan kuku, apabila tidak dicuci dengan sabun, penggosokan dan pembilasan dengan air mengalir maka partikel kotoran atau feses yang mungkin mengandung Salmonella typhi dapat dipindah ke makanan yang sedang dimakan (Paputungan, 2016). Penularan demam tifoid dapat terjadi melalui berbagai cara yang dikenal degan $5 \mathrm{~F}$ yaitu Food (makanan), Fingers (jari tangan/kuku), Fly (lalat), dan Faeces (tinja). Feses dan muntah dari penderita demam tifoid dapat menularkan bakteri Salmonella typhi kepada orang lain. Bakteri tersebut dapat ditularkan melalui perantara lalat. Apabila orang tersebut kurang memperhatikan kebersihan dirinya, maka Salmonella typhi akan masuk ke tubuh orang yang sehat (Zulkoni, 2011). Alasan responden tidak mencuci tangan sebelum makan adalah suatu kebiasaan karena memakan menggunakan sendok. Sehingga tidak lagi diperlukan proses mencuci tangan dengan sabun. Hal ini diperkuat dengan penelitian Rakhman (2009) menyatakan bahwa tidak mencuci tangan dengan sabun sebelum makan berhubungan dengan kejadian demam tifoid pada orang dewasa $(p=0.002 ; \quad \mathrm{OR}=1.625$; $95 \% \mathrm{CI}=1.497-4.602$ ).

Hasil analisis bivariat dengan uji Fisher diperoleh $p$-value $=0,48(\mathrm{p}>0,05)$ sehingga $\mathrm{Ho}$ diterima yang berarti tidak terdapat hubungan antara Kebiasaan CTPS setelah BAB dengan kejadian demam tifoid di Wilayah Kerja Puskesmas Ngaliyan. Hal yang diduga menyebabkan tidak adanya hubungan antara kebiasaan cuci tangan dengan sabun setelah BAB yaitu penerapan cuci tangan dengan sabun pada kelompok kasus dan kontrol. Sehingga hal tersebut dapat memutus rantai penularan bakteri Salmonella typhii. Orang yang tidak sering mencuci tangan dengan sabun berisiko tertular penyakit demam tifoid. Penularan dari bakteri Salmonella typhi terjadi melalui konsumsi makanan atau air terkontaminasi dengan ekskreta dari kasus demam tifoid atau pembawa bakteri yang tidak bergejala. Sehingga ketika seseorang tidak mencuci tangan dengan sabun setelah buang air besar akan memperbesar kemungkinan terjadi kekambuhan pada penderita dan dapat menjadi sumber penularan ke orang lain.

Hasil analisis bivariat dengan uji chi-square diperoleh $p$-value $=0,22(p>0,05)$ sehingga Ho diterima yang berarti tidak terdapat hubungan antara kondisi kuku jari tangan dengan kejadian demam tifoid di Wilayah Kerja Puskesmas Ngaliyan. Menurut Disease Society of America, kondisi kuku yang panjangnya melebihi tiga milimeter dari ujung jari bisa menyimpan bakteri dan jamur berbahaya, kuku merupakan tempat potensial bagi kuman serta bakteri bersarang yang menyebabkan berbagai penyakit mudah datang.. Kondisi kuku responden kasus yang panjang kotor dan pendek kotor lebih besar dibandingkan kelompok kontrol. Hal ini diduga karena responden kasus lebih jarang memotong kuku daripada responden kontrol. Sebagian besar responden kasus memotong kuku lebih dari 2 minggu sebelum terjangkit demam tifoid. Seseorang yang membiarkan kuku bertambah panjang maka memperbesar kemungkinan masuknya bakteri Salmonella typhi ke kuku jari melalui feses. Sehingga pada saat 
Tabel 3. Hasil Analisis Multivariat Hubungan antara Kondisi Jamban, Kebiasaan Jajan di TPM, dan Personal Hygiene dengan Kejadian Demam Tifoid

\begin{tabular}{lllllll}
\hline Variabel & Wald & $P$ & Exp. (B) & & \multicolumn{2}{c}{$95 \%$ C.I Exp (B) } \\
\cline { 6 - 7 } & & & & Lower & Upper \\
\hline Perilaku Jajan di Rumah Makan & 4,410 & 0,036 & 3,411 & 1,085 & 10.718 \\
Perilaku Jajan di Pedagang Kaki Lima & 7,059 & 0,008 & 4,491 & 1,483 & 13,603 \\
\hline Konstanta & 12,125 & 0,000 & 0,016 & & \\
\hline
\end{tabular}

dibersihkan, masih ada bakteri yang tertinggal di dalam kuku. Salmonella, non-typhi salmonellae, Campylobacter dan E. coli dapat bertahan hidup di ujung jari dan permukaan lain untuk periode waktu yang berbeda dan dalam beberapa kasus bahkan setelah mencuci tangan (Rane, 2011). Namun untuk mencegah masuknya bakteri Salmonella typhi kedalam tubuh setidaknya memotong kuku dalam jangka waktu satu minggu sekali dan selalu mencuci tangan dengan menggosok kuku jari tangan setelah beraktifitas.

Hasil pengolahan data multivariat dapat dilihat variabel bebas yang berkontribusi kuat sebagai faktor risiko kejadian demam tifoid adalah perilaku jajan di pedagang kaki lima. dikarenakan variabel tersebut memiliki nilai $p$ paling kecil atau nilai OR paling besar. Sehingga orang dewasa yang memiliki perilaku jajan di pedagang kaki lima $\geq 3$ kali seminggu berisiko menderita demam tifoid 4,491 kali dibandingkan dengan orang dewasa yang memiliki perilaku jajan di pedagang kaki lima < 3 kali seminggu.

Hal ini juga diperkuat pada penelitian Ruriani (2010) bahwa makanan nasi goreng pada pedagang kaki lima di Jember menunjukkan bahwa 4 dari 15 sampel nasi goreng diinvestigasi mengandung Salmonella paratyphi tipe B dan C. Makanan yang sudah dingin dan dibiarkan di tempat terbuka merupakan media mikroorganisme yang lebih disukai. Selain penderita tifoid, sumber penularan utama berasal dari carrier (Widoyono, 2011).

Berdasarkan Kepmenkes Nomor 1098/Menkes/SK/VII/2003 tentang Persyaratan Higiene Sanitasi Rumah Makan dan Restoran, persyaratan higiene sanitasi yang harus dipenuhi meliputi persyaratan lokasi, persyaratan fasilitas sanitasi, persyaratan bahan makanan dan makanan jadi, persyaratan pengolahan makanan, persyaratan penyimpanan bahan makanan dan makanan jadi, persyaratan penyajian makanan jadi, dan persyaratan peralatan yang digunakan. Pelaksanaan kegiatan higiene sanitasi pangan merupakan salah satu aspek dalam menjaga keamanan pangan yang harus dilaksanakan secara terstruktur dan terukur dengan kegiatan, sasaran dan ukuran kinerja yang jelas, salah satunya dengan mewujudkan Tempat Pengelolaan Makanan yang memenuhi syarat kesehatan.

\section{PENUTUP}

Simpulan penelitian menunjukan bahwa terdapat hubungan antara perilaku jajan di rumah makan, perilaku jajan di pedagang kaki lima, dan kebiasaan CTPS sebelum makan dengan kejadian demam tifoid di Wilayah Kerja Puskesmas Ngaliyan. Sedangkan tidak terdapat hubungan antara kondisi jamban, perilaku jajan di pedagang keliling, kebiasaan CTPS setelah $\mathrm{BAB}$, dan kondisi kuku jari tangan dengan kejadian demam tifoid di Wilayah Kerja Puskesmas Ngaliyan. Kelemahan penelitian ini yaitu tidak dapat mengukur langsung keberadaan bakteri Salmonella typhi pada penjamah makanan. Sehingga saran bagi peneliti lain yang akan mengambil tema dan di wilayah yang sama diharapkan agar mengembangkan penelitian tentang keberadaan Salmonella typhi yang ada di tempat pengelolaan makanan yang ada di Wilayah Kerja Puskesmas Ngaliyan. Perlu ditambah untuk meneliti tentang efektifitas edukasi sanitasi makanan 
untuk tempat pengelolaan makanan di Wilayah Kerja Puskesmas Ngaliyan.

\section{DAFTAR PUSTAKA}

Alamsyah, D. 2013. Prinsip Dasar Ilmu Kesehatan Masyarakat. Yogyakarta: Nuha Medika.

Alba, S., Bakker, M. I., Hatta, M., Scheelbeek, P. F. D., Dwiyanti, R., Usman, R., Smits, H. L. 2016. Risk Factors of Typhoid Infection in The Indonesian Archipelago. PLoS ONE, 11(6): 1-14.

Andayani, \& Fibriana, A. I. 2017. Kejadian Demam Tifoid di Wilayah Kerja Puskesmas Karangmalang. HIGEIA (Journal of Public Health Research and Development), 1(1): 51-57.

Febriana, D., Siswanto, Y., \& Pranowowati, P. 2015. Hubungan antara Sanitasi Lingkungan dengan Kejadian Demam Tifoid di Wilayah Kerja Puskesmas Lerep Kabupaten Semarang. Jurnal Gizi dan Kesehatan, 7(13): 90-104.

Kobayashi, T., Kutsuna, S., Hayakawa, K., Kato, Y., Ohmagari, N., Uryu, H., Ohnishi, M. 2016. Case report: An outbreak of food-borne typhoid fever due to salmonella enterica serotype typhi in Japan reported for the first time in 16 years. American Journal of Tropical Medicine and Hygiene, 94(2): 289-291.

Lee, H. K., Halim, H. A., Thong, K. L., \& Chai, L. C. 2017. Assessment of Food Safety Knowledge, Attitude, Self-Reported Practices, and Microbiological Hand Hygiene of Food Handlers. Environmental Research and Public Health, 14(1): 55.

Monney, I., Agyei, D., \& Owusu, W. 2013. Hygienic Practices among Food Vendors in Educational Institutions in Ghana: The Case of Konongo. Foods, 2(3): 282-294.

Mubarak, W. 2009. Ilmu Kesehatan Masyarakat: Teori dan Aplikasi. Jakarta: Salemba Medika

Muyanja, C., Nayiga, L., Brenda, N., \& Nasinyama, G. 2011. Practices, Knowledge and Risk Factors of Street Food Vendors in Uganda. Food Control, 22(10): 1551-1558.

Nuruzzaman, H. 2016. Analisis Risiko Kejadian Demam Tifoid berdasarkan Kebersihan Diri dan Kebiasaan Jajan di Rumah. Jurnal Berkala Epidemiologi, 4(1): 74-86.

Omemu, A. M., \& Aderoju, S. T. 2008. Food Safety Knowledge and Practices of Street Food Vendors in The City of Abeokuta, Nigeria. Food Control, 19(4): 396-402.
Onyeneho, S. N., \& Hedberg, C. W. 2013. An Assessment of Food Safety Needs of Restaurants in Owerri, Imo State, Nigeria. Environmental Research and Public Health, 10(18): 3296-3309.

Paputungan, W. 2016. Hubungan antara Perilaku Hidup Bersih dan Sehat dengan Kejadian Demam Tifoid di Wilayah Kerja Puskesmas Upai Kota Mobagu tahun 2015. Jurnal Ilmiah Farmasi, 5(2): 266-275.

Pramitasari, O. 2013. Faktor Risiko Kejadian Penyakit Demam Tifoid pada Penderita yang Dirawat di Rumah Sakit Umum Daerah Ungaran. Jurnal Kesehatan Masyarakat, 2(1): 108-117.

Rakhman, A. 2009. Faktor - Faktor Risiko yang Berpengaruh Terhadap Kejadian Demam Tifoid pada Orang Dewasa. Berita Kedokteran Masyarakat, 25(4): 167-175.

Rane, S. 2011. Street Vended Food in Developing World: Hazard Analyses. Indian Journal Microbiol, 51(1): 100-106.

Ruriani, E., \& Nurhayati. 2010. Investigasi Bacillus cereus dan Salmonella pada Nasi Goreng Pedagang Kaki Lima di Sekitar Kampus Universitas Jember. Agrotek, 4(1): 68-75.

Seran, E., Palandeng, H., dan Kallo, V. 2015. Hubungan Personal Hygiene dengan Kejadian Demam Tifoid di Wilayah Kerja Puskesmas Tumaratas. Ejournal Keperawatan, 3(2): 1-8.

Siddiqui, T. R., Bibi, S., Mustufa, M. A., Ayaz, S. M., \& Khan, A. 2015. High Prevalence of Typhoidal Salmonella Enterica Serovars Excreting Food Handlers in Karachi-Pakistan: A Probable Factor for Regional Typhoid Endemicity. Journal of Health, Population and Nutrition, 33(1): 1-9.

Susanna, D., \& Indrawani, Y. M. 2010. Kontaminasi Bakteri Escherichia coli pada Makanan Pedagang Kaki Lima di Sepanjang Jalan Margonda Depok, Jawa Barat. Jurnal Kesehatan Masyarakat Nasional, 5(3): 110-115.

Syafdalni, S., Hasan, W., \& Marsaulina, I. 2014. Perbedaan Sanitasi Pengelolaan Rumah Makan dan Restoran Berdasarkan Tingkat Mutu (Grade A, B, dan C) di Kota Medan Tahun 2013. Jurnal Kesehatan Lingkungan dan Keselamatan Kerja, 3(2): 1-8.

UI, S. P. F. 2010. Buku Ajar Mikrobiologi Kedokteran Edisi Revisi. Jakarta: Bina Rupa Aksara.

Widoyono. 2011. Penyakit Tropis Epidemiologi, Penularan, Pencegahan, dan Pemberantasannya. Jakarta: PT.Gelora Aksara Pratama. 
Anggit A. P. / Faktor Lingkungan / HIGEIA 2 (4) (2018)

Yonathan, D. Y. 2013. Hubungan antara Kualitas Sarana dan Prasarana Rumah dan Perilaku Sehat dengan Kejadian Demam Tifoid di Wilayah Kerja Puskesmas Ngaliyan Kota
Semarang. Jurnal Kesehatan Masyarakat, 2(1): 390-398.

Zulkoni, A. 2011. Parasitologi. Yogyakarta: Nuha Medika. 